International Journal of Automotive and Mechanical Engineering (IJAME)

ISSN: 2229-8649 (Print); ISSN: 2180-1606 (Online); Volume 8, pp. 1096-1107, July-December 2013

CUniversiti Malaysia Pahang

DOI: http://dx.doi.org/10.15282/ijame.8.2013.1.0089

\title{
CFD INVESTIGATION OF IN-CYLINDER AIR FLOW TO OPTIMIZE NUMBER OF GUIDE VANES TO IMPROVE CI ENGINE PERFORMANCE USING HIGHER VISCOUS FUEL
}

\author{
Idris Saad $^{1,2 *}$ and S. Bari ${ }^{2}$ \\ ${ }^{1}$ Automotive Research and Testing Centre (ARTeC), \\ Universiti Teknologi MARA, 40450 Shah Alam, Malaysia \\ Email: edris_sd@yahoo.com / idris.saad@mymail.unisa.edu.au \\ Phone: +603-5543-5190; Fax: +609-5543-5160 \\ ${ }^{2}$ School of Advanced Manufacturing, University of South Australia, \\ Mawson Lakes, South Australia, 5095
}

\begin{abstract}
This paper investigates the in-cylinder air flow of a compression ignition (CI) engine modified by a guide vane swirl and tumble device (GVSTD) where the number of GVSTD vanes was varied to optimize its dimension to improve the CI engine performance using higher viscous fuel (HVF). Hence, eleven 3D CI engine models were developed; a base model and 10 GVSTD models, via SolidWorks. Computational fluid dynamics (CFD) were performed by utilizing ANSYS-CFX and simulated under motored conditions for two continuous complete cycles. The results are presented of the simulation of in-cylinder pressure, turbulence kinetic energy (TKE) and velocity during the fuel injection period until expansion. The recorded increments from six vanes of GVSTD were about $1.3 \%, 0.2 \%$ and $22 \%$ of the above results. Hence, this paper concludes that GVSTD has the potential to improve CI engine performance using HVF.
\end{abstract}

Keywords: Engine simulation; CFD; guide vane; higher viscous fuel (HVF); in-cylinder air flow.

\section{INTRODUCTION}

In 1900, 'the father of the CI engine', Dr Rudolf Diesel, demonstrated his engine using peanut oil as a fuel at the World Exposition in Paris, France (Murugesan et al., 2009). This proved that the CI engine could run using various vegetable oil-based and animal fat-based fuels which were renewable and could solve the problem of the receding world supply of crude oil (Greenberger, 2013; Kamil, Rahman, \& Bakar, 2011). For these reasons, many researchers have studied the performance of a CI engine fueled by this type of fuel. Pramanik investigated a single cylinder, water-cooled open combustion CI engine, comparing its performance when fueled by jatropha curcas oil and petrodiesel (Pramanik, 2003; Rahim, Mamat, Taib, \& Abdullah, 2012). In his experiment, at maximum load, the engine consumed about $0.52 \mathrm{~kg} / \mathrm{kWh}$ of jatropha curcas and produced about $17.5 \%$ of brake thermal efficiency, but it only consumed about 0.302 $\mathrm{kg} / \mathrm{kWh}$ of petro-diesel fuel while producing $27 \%$ of brake thermal efficiency. A study by Yahya and Norhisyam (2012) compared waste cooking oil (WCO) as a CI engine fuel with petro-diesel. In their experiment on a $600 \mathrm{cc}$ CI engine, model Lister ST1, the engine consumed about $0.38 \mathrm{~L} / \mathrm{kWh}$ of $\mathrm{WCO}$ at $70 \%$ engine load while it only consumed about $0.21 \mathrm{~L} / \mathrm{kWh}$ of petro-diesel in similar conditions. Ramadhas, Jayaraj, and Muraleedharan (2004) reviewed 42 studies about the use of vegetable oils as CI 
engine fuel. Based on their conclusion, the performance of a CI engine fueled by vegetable oil was lower than when fueled by petro-diesel. The main problem was that the properties of the alternative fuels for the CI engine were relatively low-grade compared to petro-diesel. This research has reviewed several articles about the properties of vegetable oil as CI engine fuel from 2001 until 2012, comparing them with those of petro-diesel, and the results are tabulated in Table 1.

Table 1. Properties of vegetable oil compared to petro-diesel

(Altın et al., 2001; Pugazhvadivu \& Jeyachandran, 2005; Senthil Kumar et al., 2005; Agarwal \& Agarwal, 2007; Murugesan et al., 2009; Misra \& Murthy, 2011; Chauhan et al., 2012; Bousbaa et al., 2012; Yahya \& Norhisyam, 2012).

\begin{tabular}{cccccc}
\hline $\begin{array}{c}\text { Fuel } \\
\text { Properties }\end{array}$ & $\begin{array}{c}\text { Kinematic } \\
\text { Viscosity at } \\
25-40^{\circ} \mathrm{C} \\
{\left[\mathrm{mm}^{2} / \mathrm{s}\right]}\end{array}$ & $\begin{array}{c}\text { Cetane } \\
\text { Number }\end{array}$ & $\begin{array}{c}\text { Higher } \\
\text { Heating } \\
\text { Value } \\
{[\mathrm{MJ} / \mathrm{kg}]}\end{array}$ & $\begin{array}{c}\text { Density } \\
{[\mathrm{kg} / \mathrm{L}]}\end{array}$ & $\begin{array}{c}\text { Flash Point } \\
{\left[{ }^{\circ} \mathrm{C}\right]}\end{array}$ \\
\hline $\begin{array}{c}\text { Petro-diesel } \\
\text { Alternative } \\
\text { fuel }\end{array}$ & $2.10-5.7$ & $45-50.2$ & $\begin{array}{c}41.87- \\
45.343\end{array}$ & $\begin{array}{c}0.815- \\
0.867\end{array}$ & $70-86$ \\
\hline
\end{tabular}

As shown in Table 1, the kinematic viscosity, cetane number, higher heating value, density and flash point of the alternative fuel for the CI engine are all substandard to petro-diesel. Based on this concern, this research has grouped the alternative fuels for the CI engine ranging from vegetable oil to higher viscous fuels (HVFs). Many techniques have been used by researchers worldwide to improve the CI engine fueled by HVF. Among these are the use of HVF as an additive to petro-diesel fuel (Chauhan et al., 2012; Agarwal \& Agarwal, 2007) to reduce the consumption of petro-diesel; preheating the HVF (Pugazhvadivu \& Jeyachandran, 2005; Senthil Kumar et al., 2005) to level its viscosity; and adjusting the injection timing (Ye \& Boehman, 2012) to inject the fuel at the highest possible pressure and temperature to increase the combustion efficiency. These techniques produce better results than a CI engine fueled with HVF; however, performance was still lower than when fueled by petro-diesel. Referring to CI engine combustion theory (Heywood, 1988; Pulkrabek, 2004), higher combustion efficiency will be achieved when a high quality of petro-diesel (lower viscosity) is injected into higher pressure, temperature and turbulence of air, resulting in higher fuel evaporation, mixing and combustion. When comparing the preceding techniques by researchers worldwide with this theory, it was found that none of them was trying to improve the in-cylinder air characteristics. Because of that, this research has investigated the potential of in-cylinder air flow to improve a CI engine fueled with HVF. It is important to study the effect of improving in-cylinder air flow on the performance of CI engines run with HVF since none of research so far has been found investigate this, although it is suggested by the theory mentioned above. This can be a new contribution to the body of knowledge.

Improving in-cylinder air flow is not a new technique for improving engine performance. Techniques used have included a butterfly valve to close part of the intake manifold ( Mamat, Abdullah, Xu, Wyszynski, \& Tsolakis, 2009; Mat Yasin, Mamat, Sharma, \& Yusop, 2012); a shroud around the inlet valve (Mahmud, Cho, \& Kwak, 2009); and modification of the inlet manifold (Xin et al., 2011) to generate higher swirl 
to allow an organized air flow, thus resulting in higher volumetric efficiency which then increases the pressure, temperature and turbulence of the in-cylinder air. However, none of them were applied on a CI engine run with HVF and this research can be considered as a novelty of the present work. Considering this previous research as a base from which to develop a technique for this purpose, the simplest technique was selected, which was to use a static vane installed in front of the intake manifold to guide the air intake, which was a popular technique for the spark ignition (SI) engine. This research names that static vane the GVSTD (guide vane swirl and tumble device). As a base study, this research explores the in-cylinder air characteristics generated by the GVSTD using a simulation method which utilizes SolidWorks as a computer aided drawing (CAD) tool and ANSYS-CFX as a computational fluid dynamics (CFD) tool before conducting experiments on the engine itself. To study the in-cylinder air flow, a 3D CI engine model in accordance with the CI generator engine make and model of a HINO W04D was prepared and simulated under motored conditions as a base model before the GVSTD models were imposed on it. Table 2(a) tabulates the technical specifications of the HINO W04D. The detail of the methodology is presented in the next section.

Table 2. (a) Technical specification of HINO W04D; (b) Specification of GVSTD

\begin{tabular}{cc}
\hline & (a) \\
\hline Stroke $\times$ bore & $108 \times 104 \mathrm{~mm}$ \\
Intake system & Naturally \\
& aspirated \\
Intake diameter & $80 \mathrm{~mm}$ \\
Compression ratio & $17.9: 1$ \\
Piston crown & Concave convex \\
Injection timing & $14^{\circ} \mathrm{BTDC}$ \\
\hline
\end{tabular}

\begin{tabular}{cc}
\hline \multicolumn{2}{c}{$(\mathrm{b})$} \\
\hline Intake runner radius $(\mathrm{R})$ & $10 \mathrm{~mm}$ \\
Vane height $(\mathrm{H})$ & $0.2 \times \mathrm{R}=2 \mathrm{~mm}$ \\
Vane twist angle $(\theta)$ & $35^{\circ}$ clockwise \\
& $3,4,5,6,7,8$, \\
Vane number & $9,10,11$ and \\
& 12 vanes \\
\hline
\end{tabular}

According to the published pattern (Currie \& Lazich, 2011; Sun et al., 2011; Kim, 2003; Lin \& Yang, 2000), the design of the GVSTD depends on four main geometries; the vane number $(\mathrm{N})$, vane height $(\mathrm{H})$, vane angle $(\theta)$ and vane length $(\mathrm{L})$, as presented in Figure 1, and their dimensions play an important role in generating optimized in-cylinder air characteristics. In other words, in order to design the GVSTD, the dimensions of the geometry need to be optimized as well. This research used the parametric optimization technique to optimize all four geometries mentioned above. The parametric optimization technique was the simplest optimization technique at the time when the GVSTD was developed, as it varies the dimension of the geometries and tests them one by one. The highest possible improvement made by a particular dimension is considered as the optimized dimension for a particular geometry.

In accordance with the previous studies, the vane height was optimized at 0.2 times the radius of the intake runner (R) (Bari \& Saad, 2013; Saad et al., 2013; Saad $\&$ Bari, 2012, 2013). For the purpose of this paper, the scope has been limited to the optimization of the vane number: the other dimensions can be referred to in Table 2(b). Hence, the number of vanes was varied from 3 to 12 for a total of 10 GVSTD models. The in-cylinder pressure, turbulence kinetic energy (TKE) and velocity results were presented and compared between the base model and the GVSTD model. Finally, this research found that six is the optimum number of GVSTD vanes to be used with the other dimensions of the GVSTD geometries provided in Table 2(b). 


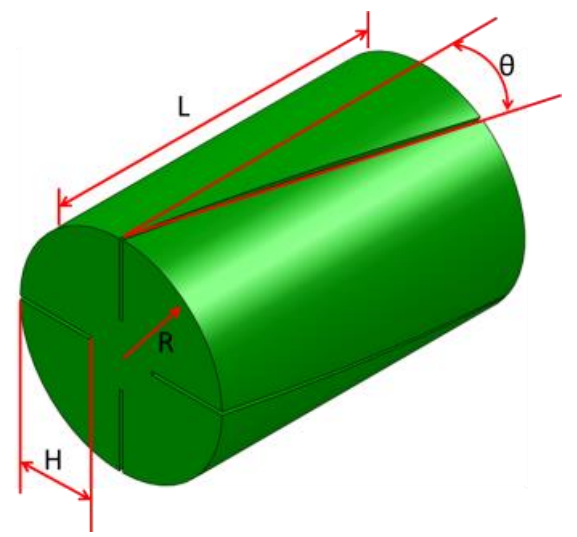

Figure 1. The geometry of the GVSTD

\section{CONSTRUCTION OF A COMPUTER SIMULATION}

The CFD simulation used in this research included the preparation of the drawing model, meshing it and setting up the analysis flow before it could be run. The steps taken to prepare the simulation model are explained as follows. As introduced earlier, the base model was replicated from a HINO W04D CI engine, with its basic technical specifications given in Table 2(a). The drawing of the base model consisted of five domains: an intake runner, intake valve, cylinder, exhaust valve and exhaust runner were prepared by using SolidWorks 2011 and are illustrated in Figure 2. Figure 2(c) shows a sample GVSTD on the base model.

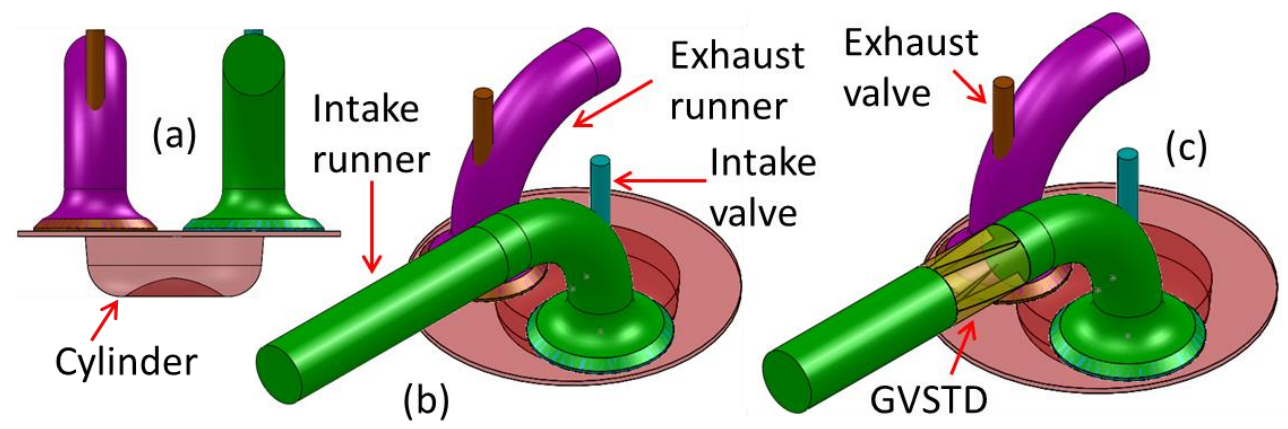

Figure 2. (a) and (b) Front and isometric views of the base model, respectively; (c) position of the GVSTD on the base model

The drawing was then exported into DesignModeler (a CAD program used in ANSYS-Workbench) because later this model would be simulated by using ANSYSCFX. The domain materials were created at this stage. The intake runner, cylinder and exhaust runner were fluid domains, while both valves were assigned as a solid domain to fulfil their function to close and open their ports. After that, the drawing model was then transferred into ANSYS-Mesh. Here, the models were meshed according to the assembly level meshing. All five domains were meshed using single mesh processes to level their quality (ANSYS Inc., 2009) in order to use the "interfaces" option to later join between the active domains in ANSYS-CFX. Note that this simulation was to be run using the moving mesh technique, which required the finest element possible to allow the element to be exponentially calculated (ANSYS Inc., 2009) as the movement of the piston during simulation. A refinement option (ANSYS Inc., 2009) was selected 
to improve the control of local mesh sizing and to allow stability for moving the mesh of approximately 495,500 combined tetrahedron, hexahedron and wedge elements. Refinement of the mesh used in the computation showed some usefulness until grid independence was reached. Increase in the number of cells in the computational domain showed a significant effect up to about the 490,000 cell range. After this point, increasing the number of cells to around 495,500 showed only a minor effect and then to over 498,000 showed no changes in the predicted in-cylinder pressure. Based on the statistics evaluation of the meshing results, about 495,500 elements were generated with roughly 107,400 nodes for each of the 11 models. The average aspect ratio and skewness were about 1.95 and 0.283 , which can be considered as high quality mesh since they are close to zero from a maximum 9.82 and 0.99 respectively.

In order to calculate the fluid flow, ANSYS-CFX used standard governing equations as given in Equations (1) - (3) for the continuity, momentum and energy equations respectively in the compressible flow condition. Based on those equations, $\rho$ is the fluid density and $t$ is the time taken to complete the simulation, since this simulation was to be run in transient mode for 10 time steps per crank angle, while $\nabla$ is the vector operator. The symbol $p$ is the fluid pressure, $S_{M}$ is the momentum source and $\tau$ is the stress tensor. As in Equation (3), $\lambda$ and $h_{t o t}$ are the thermal conductivity and the total enthalpy respectively.

Continuity:

$$
\frac{\partial \rho}{\partial t}+\nabla \cdot(\rho U)=0
$$

Momentum (Navier-Stokes): $\frac{\partial(\rho U)}{\partial t}+\nabla \cdot(\rho U \otimes U)=-\nabla p+\nabla \cdot \tau+S_{M}$

Energy:

$$
\begin{aligned}
& \frac{\partial\left(\rho h_{t o t}\right)}{\partial t}-\frac{\partial p}{\partial t}+\nabla \cdot\left(\rho U h_{t o t}\right)= \\
& \nabla \cdot(\lambda \nabla T)+\nabla \cdot(U \cdot \tau)+U \cdot S_{M}+S_{E}
\end{aligned}
$$

For the turbulence model, SST (shear stress transport) was used. This model was to combine the $k-\varepsilon$ model which gave the best result for calculating the flow in the outer region of the boundary layer and the $k-\omega$ model, which did better in the inner boundary layer (Anderson, 1995; White, 2011). As for the boundary condition, the end of the intake and the exhaust runner were assigned as an 'opening' as in the actual conditions. The other surfaces were set as a 'wall' boundary condition, but for the cylinder wall, the option of 'specifying the translation' was added to allow it to move during simulation later. The other challenge, in addition to setting up the simulation to be run in the moving mesh condition, was setting the initial conditions, since the engine was continuously running. To solve this problem, the simulations were set to be run for two continuously complete cycles, as shown in Figure 3. 


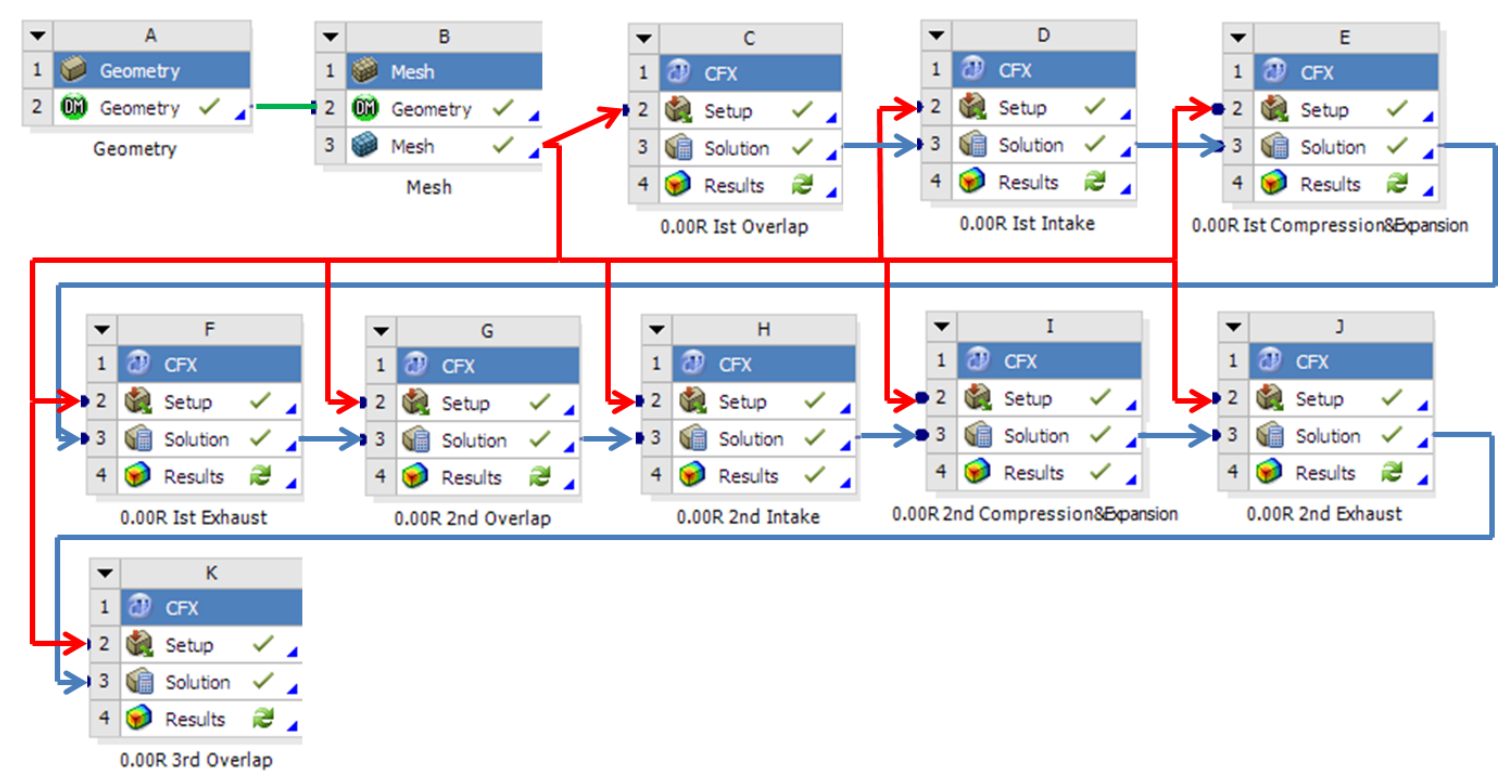

Figure 3. Simulation sequences for two continuously complete cycles

This condition allowed the initial conditions of the pressure, velocity and temperature to be set at $1 \mathrm{~atm}, 0 \mathrm{~m} / \mathrm{s}$ and $300 \mathrm{~K}$ respectively. The red and blue lines in Figure 3 indicate that the simulation used a similar model and mesh, and the initial condition for the next process was using the results from previous calculations. To complete the setting up, the convergence criteria were set at $1 \mathrm{E}-4$ with a maximum 500 coefficients loop, but based on the observation during simulation, the iteration converged around a 20 coefficients loop.

\section{RESULTS AND DISCUSSION}

This section presents the simulation results of the in-cylinder pressure, turbulence kinetic energy (TKE) and velocity around the injection period until part of the expansion. Referring to Table 2(a), the start of the injection was at $14^{\circ} \mathrm{CA}$ BTDC, i.e. at $346^{\circ} \mathrm{CA}$. Hence, this paper presents those results from $341^{\circ} \mathrm{CA}$ until $365^{\circ} \mathrm{CA}$ to predict the fuel injection, evaporation, diffusion, mixing and auto-ignition processes based on those results. In addition, simulation results within this region will provide a better perspective for estimating the effect on real cases (Basha et al., 2009; Prasad et al., 2011). The details of the simulation results are discussed in the following subsection.

\section{In-Cylinder Pressure}

Figure 4 represents the variation of in-cylinder pressure to investigate the effect of the GVSTD on the base model. It was found that the vane number and the in-cylinder air pressure developed did not have a direct linear relationship. This condition was also presented by Miles (2000) in his study about using helical intake ports to generate swirl, where the maximum pressure belonged to the low throttle, followed by the high throttle, and the lowest was with the medium throttle. 


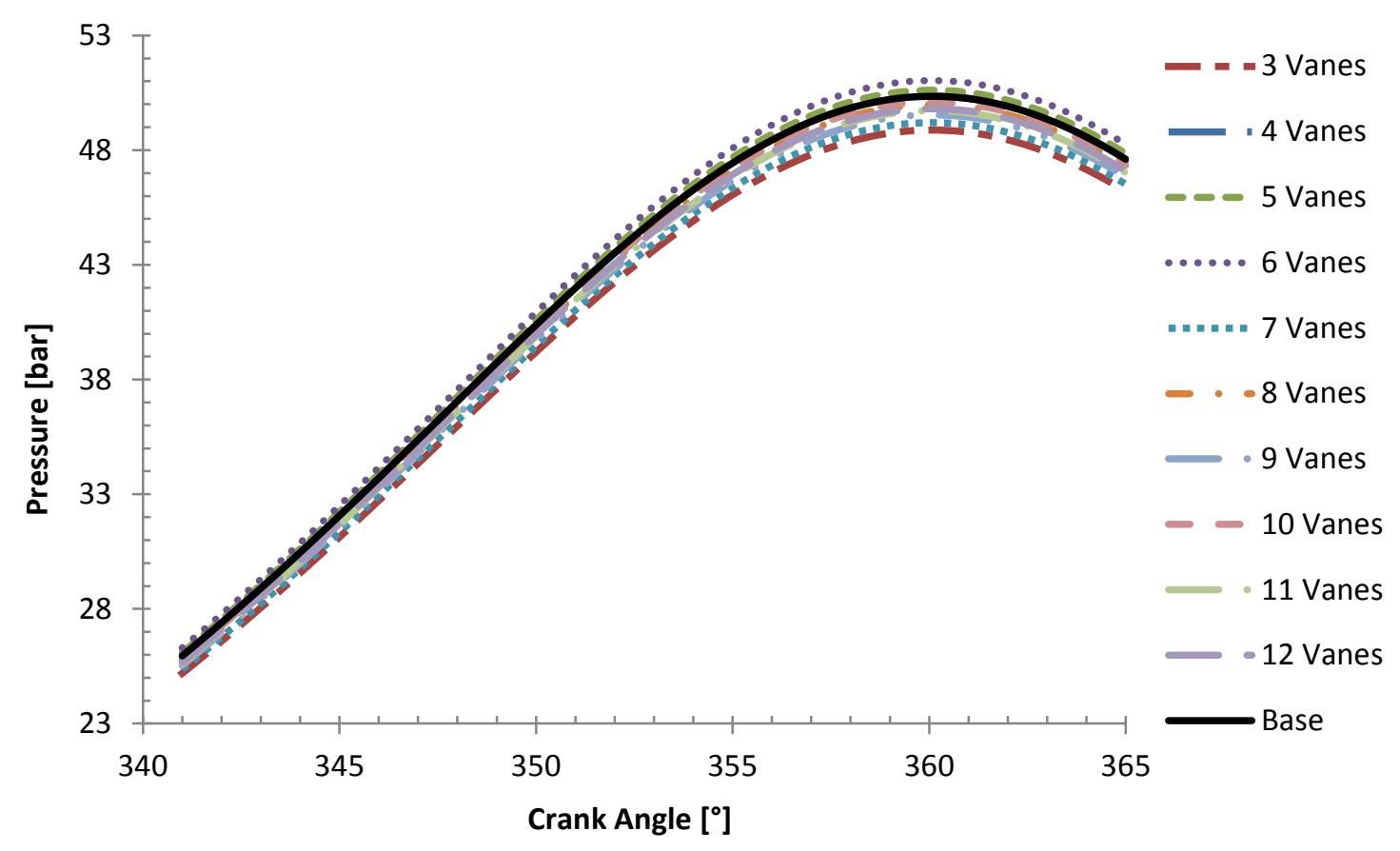

Figure 4. Maximum in-cylinder air pressure

Based on Figure 4, four, five and six vanes produced higher pressure than the base model while the maximum pressure was seen at six vanes. According to the literature (Lin \& Yang, 2000; Kim, 2003; Mamat et al., 2009; Currie \& Lazich, 2011; Sun, $\mathrm{Li}, \& \mathrm{Du}, 2011)$, inserting a vane inside the intake manifold would be an obstacle to the air flow. This was expected to happen to the other vanes. The main concept of inserting the guide vane was to guide the intake air so that the air would travel in an organized flow which would reduce the collision among air molecules, so allowing more air to enter. Three vanes each of $2 \mathrm{~mm}$ height were expected to give a low effect to guide the air flow and seven to 12 vanes with a larger surface area would hence increase the flow resistance. Referring to the results of in-cylinder pressure, six vanes were recognized as the best number of vanes since it increased by $1.3 \%$ of pressure from the maximum at about 50.3 bar of the base model. The main advantage of a higher in-cylinder pressure is that it reduces the penetration length of the injected fuel and it was also expected to expand the spray angle to make the spray cone shorter and wider. Note that the main objective of this research was that it would be used for the CI engine running on HVF, which has viscosity and density which are higher than petro-diesel, as presented in Table 1. With the increment of $1.3 \%$ of the pressure, the evaporation, diffusion and mixing processes of the HVF were also expected to increase, eventually stimulating the combustion efficiency as stated in the theory (Heywood, 1988; Pulkrabek, 2004).

\section{In-Cylinder TKE}

TKE is defined as the kinetic energy of the turbulence of the air flow (White, 2011). Higher TKE was expected to improve the process of the breaking up of the molecules of the HVF. The viscosity of the fluid, which was defined as the thickness of the fluid (White, 2011), represented the bonding of its molecules. Higher viscosity of the fluid meant stronger bonding of its molecular structure. Since the viscosity of the HVF was 
about two to 12 times that of petro-diesel, as presented in Table 1, then higher TKE would be helpful. Referring to Figure 5, TKE was approximately linearly declined towards the top dead center (TDC) which is similar to what was presented in the experiments by Payri et al. (2004) and Prasad et al. (2011). Hence, this model can be said to be a good correlation with the experimental result.

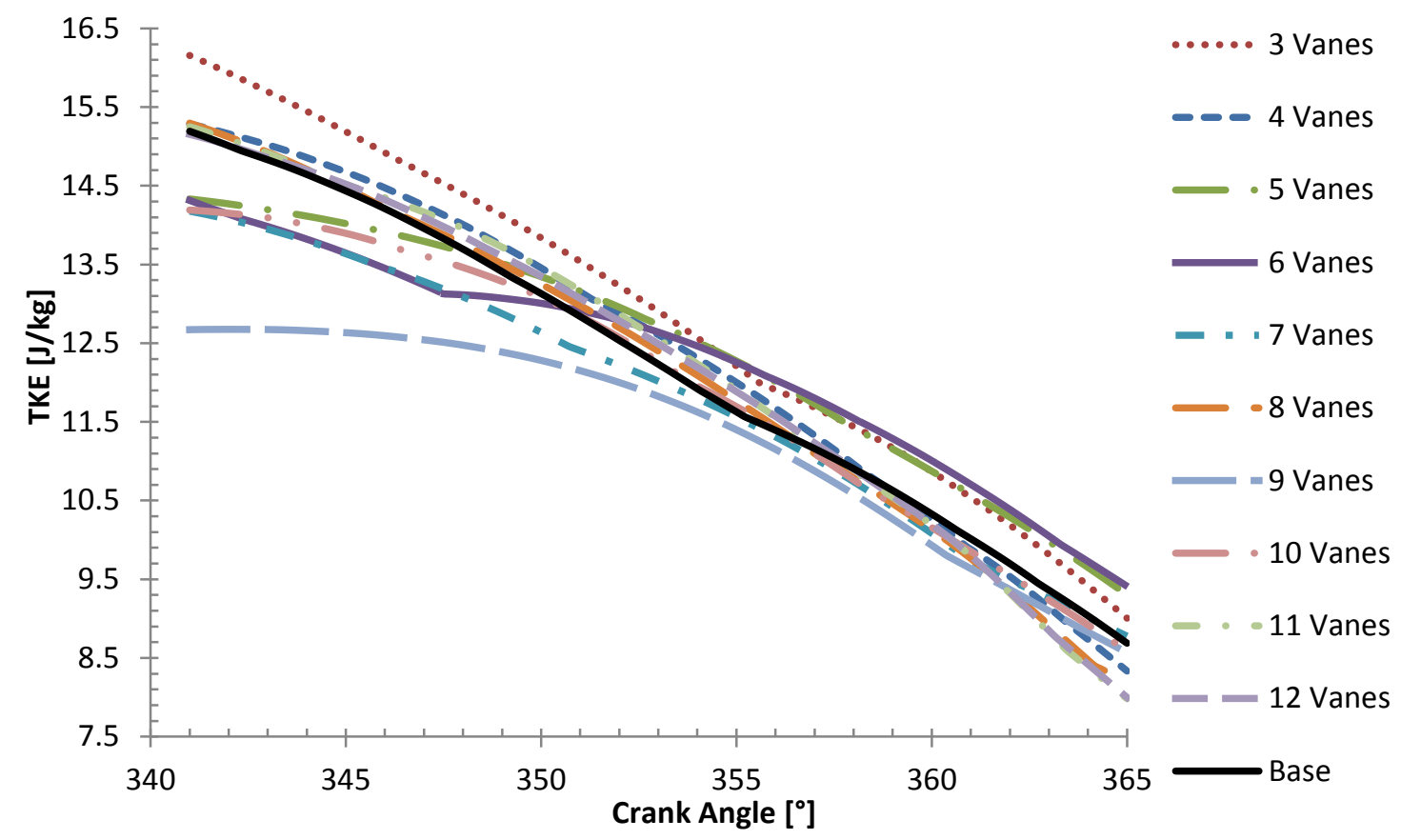

Figure 5. Maximum in-cylinder TKE

In terms of the value itself, three vanes produced higher TKE than the base model for the entire range and the other models were improving TKE more than the base model as part of the range. The six vanes which previously provided the highest improvement in the in-cylinder air pressure, improved TKE from about $350^{\circ} \mathrm{CA}$ onwards. According to different sources (Heywood, 1988; Pulkrabek, 2004; Bari et al., 2004 ), the normal ignition delay for a $\mathrm{CI}$ engine is about $6^{\circ} \mathrm{CA}$; hence $352^{\circ} \mathrm{CA}$ can be assumed to be the start of ignition (SOC) point. Therefore, six vanes improved TKE from SOI until the point of expansion. The improvement recorded by the six vanes was $2 \%$ at SOI and increased to $6.5 \%$ at TDC and $8.3 \%$ at the end of the observed data.

\section{In-Cylinder Velocity}

Figure 6 illustrates the maximum velocity of all GVSTD models compared to the base model. The main benefit of having higher velocity was that it was expected to accelerate the mixing processes after the injected fuel was expanded by the higher pressure and the molecules were being broken up by TKE. Therefore, it is presented after the other results. Since the previous results were narrowed down to the six vanes, the discussion in this result will focus on that vane number unless it produces no improvement on the base model. Based on Figure 6, the improvement made by the six vanes (shown in purple) was higher than the other models before about $363^{\circ} \mathrm{CA}$. The recorded improvements were $22.01,21.5,17.9,18.13$ and $0.1 \%$ at 341, 346, 352, 360 and $365^{\circ} \mathrm{CA}$ compared with the base model respectively. It is estimated that this result 
would help the mixing process and improve the combustion efficiency of the CI engine fueled by HVF.

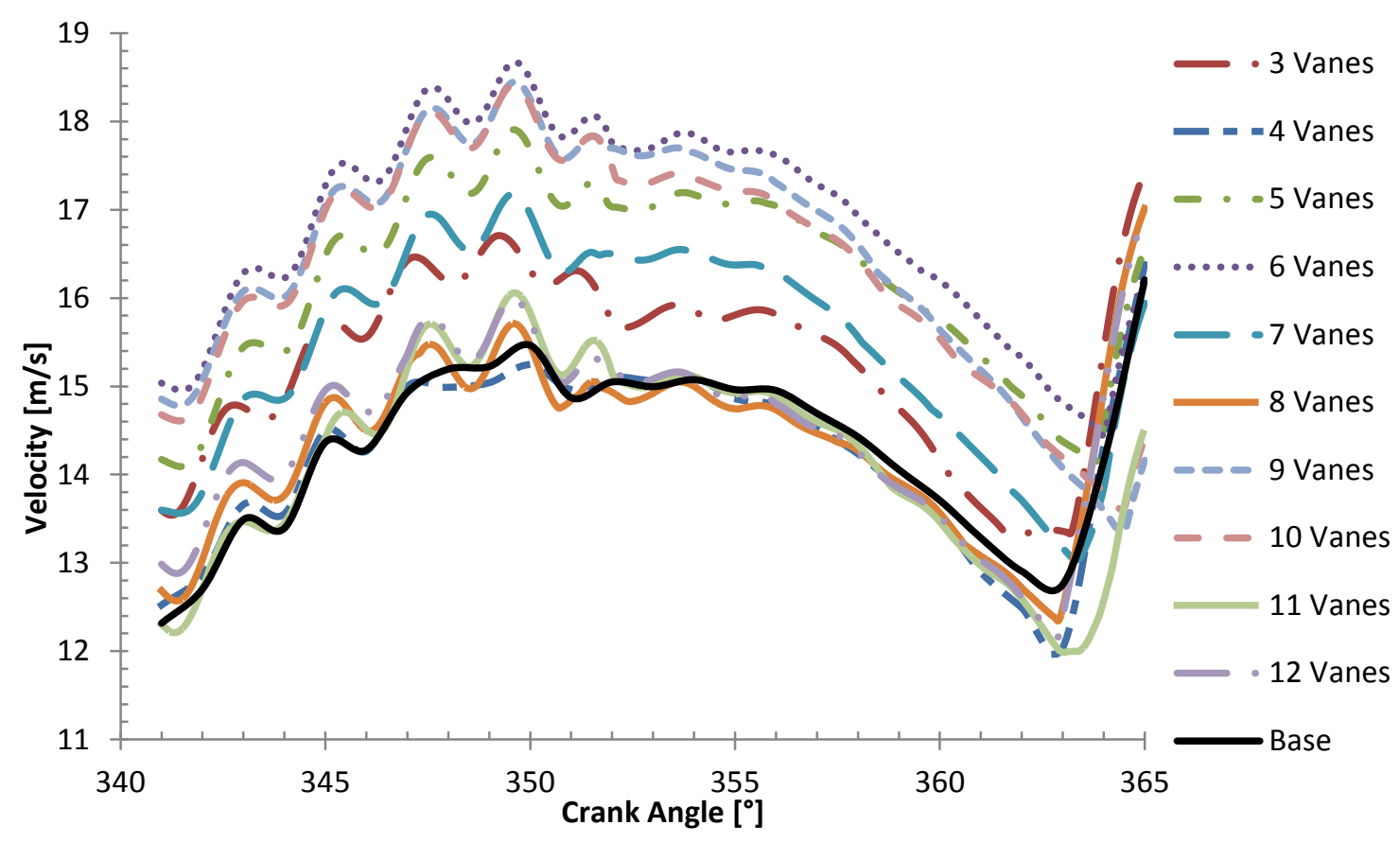

Figure 6. Maximum in-cylinder velocity

\section{Optimized Vane Number of GVSTD Geometry}

Based on the results of the in-cylinder air pressure, TKE and velocity as presented above, it was found that six vanes is clearly the best number of vanes to couple to the other GVSTD geometry as given in Table 2(b). Generally, it improves all the presented results, which were expected to improve the CI engine performance when running with HVF.

\section{CONCLUSION}

The main aim of this project was to investigate the effect of the GVSTD in improving the air flow of the CI engine in order to improve engine performance when running with HVF. It was hoped that this would offer an alternative solution to reduce the dependency on using petro-fuel, which is being reported as having the problem of receding supply. A 3D-based model CI engine which replicated the form of a naturally aspirated CI generator engine was developed by utilizing SolidWorks and undertaking a simulation using ANSYS-CFX. Ten GVSTD models with between three and 12 vanes were formed and tested one by one on the base model. The results of the in-cylinder air pressure, TKE and velocity were presented and discussed. It was found that six vanes improved about $1.3 \%$ of in-cylinder air pressure, $2 \%$ to $8.3 \%$ of TKE and a maximum of about $22 \%$ of velocity. Six vanes were chosen as the best number of vanes to be coupled with 0.2 times radius of the vane height, $35^{\circ}$ twist angle of the vane and an intake runner three times the radius of the vane length. 


\section{ACKNOWLEDGMENTS}

The first author would like to acknowledge the support of the Universiti Teknologi MARA and the Ministry of Higher Education, Malaysia for the scholarship granted to carry out this research.

\section{REFERENCES}

Agarwal, D. \& Agarwal, A. K. (2007). Performance and emissions characteristics of Jatropha oil (preheated and blends) in a direct injection compression ignition engine. Applied Thermal Engineering, 27, 2314-2323.

Altın, R., Çetinkaya, S., \& Yücesu, H. S. (2001). The potential of using vegetable oil fuels as fuel for diesel engines. Energy Conversion and Management, 42, 529538.

Anderson, J. D. (1995). Computational fluid dynamics: the basics with applications, New York: McGraw-Hill.

ANSYS Inc. (2009) CFX-Mesh.

Bari, S. \& Saad, I. (2013), CFD modelling of the effect of guide vane swirl and tumble device to generate better in-cylinder air flow in a CI engine fuelled by biodiesel. Computers \& Fluids, 84, 262-269.

Bari, S., Yu, C., \& Lim, T. (2004). Effect of fuel injection timing with waste cooking oil as a fuel in a direct injection diesel engine. Proceedings of the Institution of Mechanical Engineers, Part D: Journal of Automobile Engineering, 218, 93104.

Basha, S. M. J., Prasad, P. I., \& Rajagopal, K. (2009). Simulation of in-cylinder processes in a DI diesel engine with various injection timings. Journal of Engineering and Applied Sciences, 4(1).

Bousbaa, H., Sary, A., Tazerout, M., et al. (2012). Investigations on a compression ignition engine using animal fats and vegetable oil as fuels. Journal of Energy Resources Technology, 134, 022202.

Chauhan, B. S., Kumar, N., \& Cho, H. M. (2012). A study on the performance and emission of a diesel engine fueled with Jatropha biodiesel oil and its blends. Energy, 37, 616-622.

Currie, D. \& Lazich, I. (2011). Air supply system for an internal combustion engine. Google Patents.

Greenberger, M. (2013). Closing Wall Street's commodity and swaps betting parlors: legal remedies to combat needlessly gambling up the price of crude oil beyond what market fundamentals dictate. George Washington Law Review, 81, 20122054.

Heywood, J. B. (1988). Internal Combustion Engines Fundamentals. McGraw Hill International.

Kamil, M., Rahman, M. M., \& Bakar, R. A. (2011). Performance evaluation of external mixture formation strategy in hydrogen fueled engine. Journal of Mechanical Engineering and Sciences, 1, 87-98.

Kim, J. S. (2003). Fluid swirling device for an internal combustion engine. United States Patent. USA.

Mamat, R., Abdullah, N. R., Xu, H., Wyszynski, M. L., \& Tsolakis, A. (2009). Effect of air intake pressure drop on performance and emissions of a diesel engine operating with biodiesel and ultra low sulphur diesel (ULSD). International 
Conference on Renewable Energy and Power Quality (ICREPQ'09). Valencia, Spain.

Mahmud, M. I., Cho, H. M., \& Kwak, S.-S. (2009). Variable countercurrent distribution control (VCDC) system in IC diesel engine. Proceedings of the World Congress on Engineering II.

Mat Yasin, M. H., Mamat, R., Sharma, K. V., \& Yusop, A. F. (2012). Influence of palm methyl ester (PME) as an alternative fuel in the multicylinder diesel engine. Journal of Mechanical Engineering and Sciences, 3, 331-339.

Miles, P. C. (2000). The influence of swirl on HSDI diesel combustion at moderate speed and load. SAE International Journal.

Misra, R. D. \& Murthy, M. S. (2011). Jatropa-The future fuel of India. Renewable and Sustainable Energy Reviews, 15, 1350-1359.

Murugesan, A., Umarani, C., Subramanian, R., et al. (2009). Bio-diesel as an alternative fuel for diesel engines-A review. Renewable and Sustainable Energy Reviews, 13, 653-662.

Payri, F., Benajes, J., Margot, X., et al. (2004). CFD modeling of the in-cylinder flow in direct-injection diesel engines. Computers \& Fluids, 33, 995-1021.

Pramanik, K. (2003). Properties and use of jatropha curcas oil and diesel fuel blends in compression ignition engine. Renewable Energy, 28, 239-248.

Prasad, B. V. V. S. U., Sharma, C. S, Anand, T. N. C., et al. (2011). High swirl-inducing piston bowls in small diesel engines for emission reduction. Applied Energy, 88, 2355-2367.

Pugazhvadivu, M. \& Jeyachandran, K. (2005), Investigations on the performance and exhaust emissions of a diesel engine using preheated waste frying oil as fuel. Renewable Energy, 30, 2189-2202.

Pulkrabek, W. W. (2004). Engineering Fundamentals of the Internal Combustion Engine. Pearson Prentice Hall.

Rahim, R. Mamat, R., Taib, M. Y., \& Abdullah, A. A. (2012). Influence of fuel temperature on a diesel engine performance operating with biodiesel blended. Journal of Mechanical Engineering and Sciences, 2, 226-236.

Ramadhas AS, Jayaraj S and Muraleedharan C. (2004) Use of vegetable oils as I.C. engine fuels-A review. Renewable Energy 29: 727-742.

Saad, I. \& Bari, S. (2012). Improving air-fuel mixing in diesel engine fuelled by higher viscous fuel using guide vane swirl and tumble device (GVSTD). SAE 2013 World Congress \& Exhibition. Detroit, Michigan, USA: SAE.

Saad, I. \& Bari, S. (2013), Optimize vane length to improve in-cylinder air characteristic of CI engine using higher viscous fuel. Applied Mechanics and Materials, 393, 293-298.

Saad, I., Bari, S., \& Hossain, S. N. (2013). In-cylinder air flow characteristics generated by guide vane swirl and tumble device to improve air-fuel mixing in diesel engine using biodiesel. Procedia Engineering, 56, 363-368.

Senthil Kumar, M., Kerihuel, A., Bellettre, J., et al. (2005). Experimental investigations on the use of preheated animal fat as fuel in a compression ignition engine. Renewable Energy, 30, 1443-1456.

Lin, S.-S. \& Yang, J.-C. (2000). Intake swirl enhancing structure for internal combustion engine. United States Patent. USA.

Sun, Z., Li, X., \& Du. W. (2011). Research on swirler for intake induced swirl in DI diesel engine. IEEE, Proceedings of Computer Distributed Control and 
Intelligent Environmental Monitoring (CDCIEM), 2011 International Conference on, 275-279.

White, F. M. (2011). Fluid mechanics. New York: McGraw Hill.

Xin, X., Liu, D. X., Wang, L. Q., et al. (2011). Influence of variable swirl intake manifolds for DI diesel engine on in-cylinder air motion. Applied Mechanics and Materials, 130, 95-98.

Yahya, W. J. \& Norhisyam, M. (2012). Utilization of waste cooking oil as diesel fuel and improvement in combustion and emission. Journal of Mechanics Engineering and Automation, 2(4), 267-270.

Ye, P. \& Boehman, A. L. (2012). An investigation of the impact of injection strategy and biodiesel on engine NOx and particulate matter emissions with a commonrail turbocharged DI diesel engine. Fuel, 97, 476-488. 